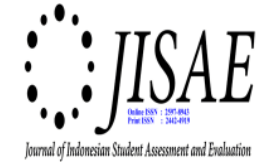

\title{
THE EFFECT OF OPTION NUMBERS ON THE ITEM INSTRUMENTS OF BELIEF ABOUT MATHEMATICS FOR JUNIOR HIGH SCHOOL STUDENTS TOWARD THE MAXIMUM RELIABILITY
}

\author{
Kisastro Saragih \\ kisastro.saragih@yahoo.com
}

\begin{abstract}
This study aims to find out the effect of option numbers on the item instruments of belief about mathematics toward the maximum reliability. The method used was experimental method with one-way analysis of variants (ANOVA) design 3x1. The population is all students of state Junior High School in Medan academic year 2014/2015. Sampling was done by multi-stage random sampling in order to obtain a sample 1,050 students of three state Junior High Schools in Medan. Study hypotheses were tested using one way ANOVA. Study results conclude that: (1) The maximum reliability of the instrument of belief about mathematics with five options is higher than the maximum reliability of the instrument of belief about mathematics with four options and three options; and (2) The maximum reliability of the instruments of belief about mathematics with four options is higher than the maximum reliability of the instruments of belief about mathematics with three options. Therefore, the more option numbers on the item instrument are, the higher the maximum reliability will be.
\end{abstract}

Keywords: belief about mathematics, option numbers, maximum reliability

Mathematics is an essential knowledge used to improve human resources. Everyone must get in touch with mathematics in their jobs. In the application, mathematics is also regulated to be a students' subject, it is the subject in Junior High School for instance.

In learning mathematics, students' belief affects their learning process a lot. Belief about mathematics is a students' belief on that they could learn mathematics well. Their belief contributes their better model and concept in learning mathematics (Schoenfeld, 1992: 68). Students' model and concept in learning mathematics will be different if their belief is different one another. Therefore, it is necessary to measure students' belief about mathematics when they learn it.

To measure the students' belief about mathematics needs some instruments to determine their belief about it. The instruments will be used to collect the data. The instruments can consist of test and non-test instruments, but non-test instruments in Likert scale will be used in measuring the belief.

Basically, Likert scale consists of five options; they are Very Approved, Approved, Doubtful, Disapproved, and Very Disapproved. But in this case, Mueller (1986: 12) stated that some scale makers have seven options, and some others have four or five options (without any midpoints). Therefore, Likert scale can be modified only on the same base.

This study uses scales with three kinds of option numbers; they are scales with three options, four options, and five options that are still based on Likert scale. The measurement scale with three options has the model that is really closed to Likert scale. Both of the scales have a midpoint of the attitude but they are different in the option numbers, the measurement scale with three options has fewer options than Likert scale. The measurement scale with four options has the model with four options that have no midpoints. And the measurement scale with five options is an original scale of Likert scale that has five options with midpoints.

Choosing the option numbers definitely affects the quality of the instruments. And the quality of the instruments shows reliability and consistency from those instruments. The numbers of the available options will affect the instrument reliability levels. The 
bigger numbers of the options will produce the higher instrument reliability levels, and the smaller numbers will produce the lower ones (Mueller, 1986: 382).

Relating with reliability, both researchers and practitioners use uni-dimensional reliability more and they use alpha Cronbach the most. But this study uses multidimensional reliability because the latent variables are used as the instrument variables. Therefore, the compatible reliability is the multidimensional reliability, and in this case, it is a maximum reliability. Thus, this study will analyze how big the option numbers affect the belief about Junior High School mathematics toward the maximum reliability. The options in this study consist of five, four, and three option numbers which are compared with one another.

In etymology, Reliable means "andal". And "andal" in Indonesian formal dictionary means "trusted". Reliability in the measurement means that the result of the measurement will be trusted if it is repeatedly used to the measured objects. The result is always constant and never changed even it is repeatedly used to the measured objects. Reliability refers to the scores the same person achieves when he is repeatedly examined with the same test on different situations or different equivalent items. In other words, reliability is the consistency of the measurement (Anastasi dan Urbina, 1997: 63; Wiersma dan Jurs, 1990: 155).

A coefficient of the maximum reliability was introduced by Li, Rosenthal, dan Ubin in 1996 which is an expansion of Spearman-Brown's coefficient on $k$ component. This coefficient is called a maximum coefficient because the estimations on reliability are based on a calculating combination for set of items in a linier explaining optimally the measurement construct. The estimations on reliability are carried out by correlating a linier combination $(\mathrm{X})$ to its latent construct $(\mathrm{y})$. By using the algebra manipulation, this concept is finally reduced to be an equality to count the maximum reliability below (Widhiarso, 2014).

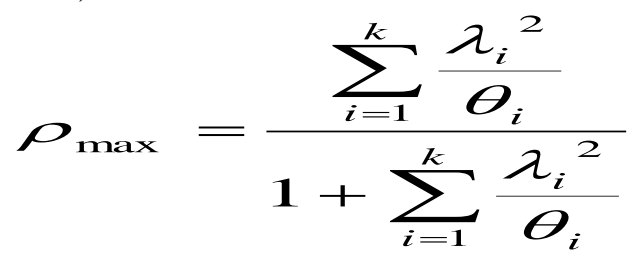

Note:

$\lambda_{i}=$ Standardized factor loading the ... (i) indicator

$\theta_{i}=$ error variance of the ... (i) indicator

According to Oxford dictionary, belief is a power to feel that it is true; to believe that it is true. Belief in Indonesia Language is "keyakinan" or "kepercayaan" (faith). Belief or faith is not easy to identify, because someone's belief is not the same as others' belief even though they state that their beliefs on something are the same. It matches what Matic (2014) stated that Beliefs are highly subjective, and they change according to someone's feelings. It shows that belief can change someone's consideration, so belief that is changed is really possible to make someone change too. In other words, belief can change someone's attitude toward something.

Mathematics is a subject everyone learns since they do not school yet until they are in a university. Mathematics has a much closed relation to the daily life because it is 
always available in every activity. In knowledge, mathematics has an important role because most of the philosophers' backgrounds are from mathematics.

Students' Belief on mathematics is a self-condition in every student's thought affecting them to think and learn the subject. Schoenfeld (1992: 47) stated that students' belief about mathematics is formed by students' metacognition; it is stated so because learning mathematics depends on the logic thinking of the thought on mathematics itself; then it will affect students' belief about mathematics toward the knowledge of mathematics in the facts.

In learning mathematics, belief affects students in developing their knowledge. The higher students' belief on mathematics subject is, the higher students' result on that subject will be, and on the contrary, the lower students' belief is, the lower students' result will be. Like Schreiber's statement by Fatade and friends (2014) on students' mathematics, that the students whose belief about the success on mathematics is high will get the higher result than the students whose belief about the success on mathematics is low.

In doing the assessment and study, the researcher needs an instrument. The instrument is a tool to collect the data of the analyzed object. Generally the instrument consists of two big components; they are test and non-test components. Non-test components are an instrument to collect students' data, and the data here is students' affective. In non-test components, students are tending to choose answers or options about their personalities. Non-test components are usually called scales.

One of the techniques used the most in the scale measurement is Likert scale, which is followed with five continuum responses showing attitude levels or feeling intensity from the felt statements (Kirkendall, 1980: 382). It means that given statements and options represent respondents' feeling and attitude. Likert scale is a scale that can be used to measure someone's or communities' attitudes, opinions, and perceptions about an educational symptom or phenomenon (Djaali dan Muljono, 2008: 28). Therefore, Likert scale can measure attitudes, opinions, and perceptions whose statements and options touch respondents' feeling and attitude so the respondents are expected to choose the options honestly.

The statements of attitude scales certainly have options following the given statements. According to Mueller (1986: 12), Likert items use the category of responses or options that have an interval from Very Approved to Very Disapproved. It means that Likert scale respondents are demanded to make a decision or to give an assessment on their attitudes. Likert scale generally has five options given to respondents; they are Very Approved, Approved, Doubtful, Disapproved, and Very Disapproved (Naga, 2013: 61).

As mentioned above, the option numbers in Likert scale are usually five options. But Mueller (1986: 12) stated that some scale makers use seven options, and some others use four or six options (without any midpoints). It means that the options in Likert scale can be modified.

\section{METHOD}

This study is carried out to the seventh grade in State Junior High School 6 Medan (SMP N 6 Medan), State Junior High School 36 Medan (SMP N 36 Medan), and State Junior High School 4 Medan (SMP N 4 Medan). This study is carried out in the even semester of academic year 2014/2015. This study is included to the experimental study with a one-way ANOVA design or one-way ANOVA $3 \times 1$. The design used in this study can be seen in this table.

Table 1. The Instrument of Belief about Mathematics with ANAVA One-Way Study Design 
Note:

\begin{tabular}{|l|l|l|}
\hline \multicolumn{1}{|c|}{ 5 options $\left(\mathrm{X}_{1}\right)$} & \multicolumn{1}{|c|}{ 4 options $\left(\mathrm{X}_{2}\right)$} & \multicolumn{1}{|c|}{ 3 options $\left(\mathrm{X}_{3}\right)$} \\
\hline$\rho_{\max 1.1}$ & $\rho_{\max 2.1}$ & $\rho_{\max 3.1}$ \\
\hline$\rho_{\max 1.2}$ & $\rho_{\max 2.2}$ & $\rho_{\max 3.2}$ \\
\hline$\rho_{\max 1.3}$ & $\rho_{\max 2.3}$ & $\rho_{\max 3.3}$ \\
\hline$\rho_{\max 1.4}$ & $\rho_{\max 2.4}$ & $\rho_{\max 3.4}$ \\
\hline$\rho_{\max 1.5}$ & $\rho_{\max 2.5}$ & $\rho_{\max 3.5}$ \\
\hline$\ldots$ & $\ldots$ & $\ldots$ \\
\hline$\ldots$ & $\ldots$ & $\ldots$ \\
\hline$\ldots$ & $\ldots$ & $\ldots$ \\
\hline$\rho_{\max 1.20}$ & $\ldots$ & $\rho_{\max 3.20}$ \\
\hline
\end{tabular}

$\rho_{\max 1 . x} \quad=$ maximum reliability value with five options

$\rho_{\max 2 . x} \quad=$ maximum reliability value with four options

$\rho_{\max 3 . x} \quad=$ maximum reliability value with three options

A free variable in this study is the numbers of the test options for belief about mathematics. And the option numbers of belief about mathematics are three, four, and five test options whereas the banded variable is the coefficient value of the maximum reliability.

The population in this study is all students of State Junior High School in Medan. The population reached in this study is all students responding the instruments of belief about mathematics. Students given the instruments of belief about mathematics are all students of the seventh grade in three State Junior High Schools in Medan. The number of the compared students filling the three instruments of belief about mathematics is 1050 students, and each instrument of belief about mathematics is filled by 350 students. The sampling technique in this study is multistage random sampling. To choose the school in district levels is also carried out randomly. The procedures in this study are: (1) Three groups of the respondents are given the instruments of belief about mathematics with different option numbers; they are 350 students for five options, 350 students for four options, and 350 students for three options, (2) The results of students' responses for the instruments are given the score, and (3) From the results of the numbers of the respondents in each group, 200 respondents are randomly taken in each group and then the coefficient of the reliability is counted, for instance the value of $\rho_{1}$. After that, the data of 200 respondents will be returned again to the groups. The 200 respondents are randomly taken again, and the coefficient of the reliability is also counted, for instance the value of $\rho_{2}$, this action will be carried out again and again until it is repeated for 20 times. Therefore, the analysis unit in this study is the reliability coefficient instrument. The instruments used in this study are the instruments of belief about mathematics.

\section{RESULT}

Data descriptions consist of three groups; they are the group of reliability coefficient for the instruments of maximum belief about mathematics with five options, the group of reliability coefficient for the instruments of maximum belief about mathematics with four options, and the group of reliability coefficient for the instruments of maximum belief about mathematics with three options. 
Those three groups will be presented in the form of descriptive statistics in the picture of boxplot, so that data distribution, homogeneity, and data tendency will be identified well. It is shown on the picture below:

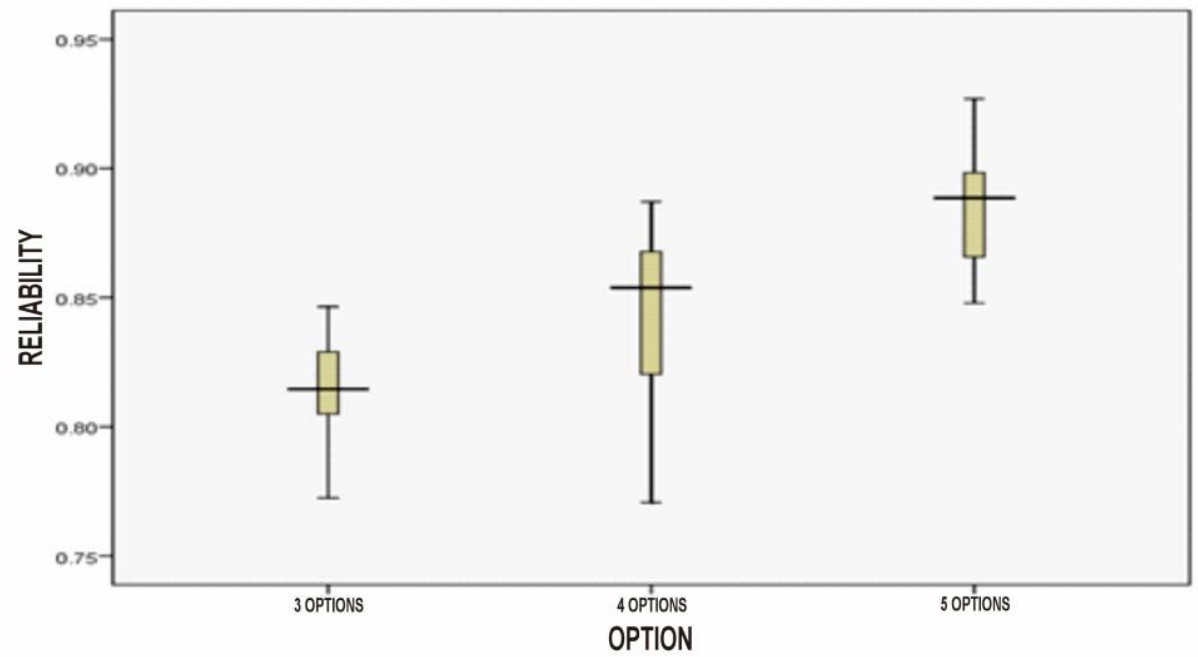

Picture 1. Boxplot of the Maximum Reliability

From the picture of boxplot above, we can interpret that the data distribution of reliability coefficient with three options is more homogeneous than the data distribution of reliability coefficient with four and five options; the data distribution of reliability coefficient with five options is more homogeneous than the data distribution of reliability coefficient with four options; the data distribution of reliability coefficient with five options is mostly collected in a low score so the data distribution of reliability coefficient is positive; the data distribution of reliability coefficient with four options is mostly collected in a low score so the data distribution of reliability coefficient is positive; the data distribution of reliability coefficient with three options is mostly collected in a high score so the data distribution of reliability coefficient is negative; the mean of reliability coefficient with five options is 0.88497 , the mean of reliability coefficient with four options is 0.843895 , the mean of reliability coefficient with three options is 0.82161 ; the variant of reliability coefficient with five options is 0.0004 , the variant of reliability coefficient with four options is 0.001 , the variant of reliability coefficient with three options is 0.0006 .

As the requirements to examine the inferential statistical hypotheses, examining the distribution of the normal and homogeneous data is carried out. Examining the normality is carried out to identify that the samples are from the population with a normal distribution. In the data analysis of this study, the normality test of Liliefors is carried out on the level of $\alpha=0.05$. To calculate the normality, the criteria of the test is accepting $\mathrm{H}_{0}$ if $\mathrm{L}_{\text {counting }}<$ $\mathrm{L}_{\text {table. }}$ It means that the data is from the population with a normal distribution.

To calculate the normality of the reliability coefficient data for the instruments of belief about mathematics with five options shows that $\mathrm{L}_{\text {counting }}=0.1319$ whereas $\mathrm{L}_{\text {table }}$ on the level of $\alpha=0.05$ with the data number of 20 is 0.19 . It means that $\mathrm{L}_{\text {counting }}<\mathrm{L}_{\text {table }}$. Therefore, accepting $\mathrm{H}_{\mathrm{o}}$ means that the data is from the population with a normal distribution. To calculate the normality of the reliability coefficient data for the instruments of belief about mathematics with five options shows that $\mathrm{L}_{\text {counting }}=0.1406$ whereas $\mathrm{L}_{\text {table }}$ on the level of $\alpha=0.05$ with the data number of 20 is 0.19 . It means that $\mathrm{L}_{\text {counting }}<\mathrm{L}_{\text {table }}$. 
Therefore, accepting $\mathrm{H}_{0}$ means that the data is from the population with a normal distribution. To calculate the normality of the reliability coefficient data for the instruments of belief about mathematics with three options shows that $\mathrm{L}_{\text {counting }}=0.0656$ whereas $\mathrm{L}_{\text {table }}$ on the level of $\alpha=0.05$ with the data number of 20 is 0.19 . It means that $\mathrm{L}_{\text {counting }}<\mathrm{L}_{\text {table. }}$. Therefore, accepting $\mathrm{H}_{\mathrm{o}}$ means that the data is from the population with a normal distribution.

The result of examining the homogeneity of the reliability coefficient groups for the instruments of belief about mathematics shows that $\chi_{\text {counting }}^{2}=3.914$ whereas $\chi_{\text {table }}^{2}$ on the level of $\alpha=0.05 \mathrm{dk} 2$ is 5.591 . Therefore, $\chi_{\text {counting }}^{2} \chi_{\text {table. It means that the variant groups }}^{2}$ have a homogeneous data.

Examining the hypotheses of the study is carried out by one-way analysis of variants (ANOVA) technique; it aims to identify the reliability coefficient difference between the instruments of belief about mathematics with five, four, and three options. The result of calculating data analysis of one-way ANOVA test can be seen in the following table:

Table 2. One-Way ANOVA

\begin{tabular}{|l|l|l|l|l|l|l|}
\hline $\begin{array}{c}\text { Variant } \\
\text { Souces }\end{array}$ & \multicolumn{1}{|c|}{$\mathrm{JK}$} & $\mathrm{Db}$ & $\mathrm{RJK}$ & $\mathrm{F}_{\text {counting }}$ & $\begin{array}{c}\mathrm{F}_{\text {table }} \\
(\alpha=0.05)\end{array}$ & Note \\
\hline Between & 0.041 & 2 & 0.02066089 & 30.767 & 3.16 & Significant \\
\hline In & 0.038 & 57 & 0.000672 & & & \\
\hline Total & 0.079 & 59 & & & & \\
\hline
\end{tabular}

Based on the result of calculating one-way ANOVA, it shows that $\mathrm{F}_{\text {counting }}=30.767$ whereas $\mathrm{F}_{\text {table }}$ with $\mathrm{db}$ the numerator of 2 and the denominator of 57 on the level of $\alpha=$

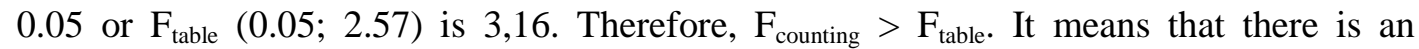
average difference of the reliability coefficient value for the instruments with five, four, and three options. So, it is continued with examining tukey, and this examining aims to identify which group is higher.

Based on the tukey test of the reliability coefficient for the instruments of belief about mathematics with five and four options, it shows that $\mathrm{Q}_{\text {counting }}=7.08$ whereas $\mathrm{Q}_{\text {table }}=$ 3.406. So, $\mathrm{Q}_{\text {counting }}>\mathrm{Q}_{\text {table. }}$ Therefore, $\mathrm{H}_{0}$ is rejected. It means that there is an average difference of the reliability coefficient value for the instruments of belief about mathematics with five and four options. The average of $\rho_{\max 1}=0.88497$ whereas the average of $\rho_{\max 2}=0.843895$. It means that the reliability coefficient for the instruments of belief about mathematics with five options is higher than the reliability coefficient for the instruments of belief about mathematics with four options.

Based on the tukey test of the reliability coefficient for the instruments of belief about mathematics with five and three options, it shows that $\mathrm{Q}_{\text {counting }}=10.93$ whereas $\mathrm{Q}_{\text {table }}$ $=3.406$. So, $\mathrm{Q}_{\text {counting }}>\mathrm{Q}_{\text {table }}$. Therefore, $\mathrm{H}_{0}$ is rejected. It means that there is an average difference of the reliability coefficient value for the instruments of belief about mathematics with five and three options. The average of $\rho_{\max 1}=0.88497$ whereas the average of $\rho_{\max 3}=0.82161$. It means that the reliability coefficient for the instruments of belief about mathematics with five options is higher than the reliability coefficient for the instruments of belief about mathematics with three options.

Based on the tukey test of the reliability coefficient for the instruments of belief about mathematics with four and three options, it shows that $\mathrm{Q}_{\text {counting }}=3.84$ whereas $\mathrm{Q}_{\text {table }}=$ 
3.406. So, $\mathrm{Q}_{\text {counting }}>\mathrm{Q}_{\text {table }}$. Therefore, $\mathrm{H}_{0}$ is rejected. It means that there is an average difference of the reliability coefficient value for the instruments of belief about mathematics with four and three options. The average of $\rho_{\max 2}=0.843895$ whereas the average of $\rho_{\max 3}=0.82161$. It means that the reliability coefficient for the instruments of belief about mathematics with four options is higher than the reliability coefficient for the instruments of belief about mathematics with three options.

\section{DISCUSSION}

The result of this study shows that there is a difference between the instruments of belief about mathematics with different option numbers; they are five, four, and three option numbers. The difference of the varied belief option numbers affects the difference of the reliability. Thus, the more the option numbers are, the higher the variants will be and the higher the variants are, the higher the reliability coefficients will be. It matches things Siti Muslihah Hadi (2013) found; they are (1) there is an effect on the numbers of response categories toward the reliability of mathematics instruments, (2) the reliability of mathematics disposition instruments with seven response categories is higher than the reliability of mathematics disposition instruments with five response categories, (3) the reliability of mathematics disposition instruments with seven response categories is higher than the reliability of mathematics disposition instruments with four response categories, (4) the reliability of mathematics disposition instruments with six response categories is higher than the reliability of mathematics disposition instruments with four response categories. It means that the more the option numbers are, the higher the instruments of the reliability coefficients will be. It matches what Mueller stated from Guilford's statement (1986: 386) that the reliability will increase if the option numbers increase.

In this study, it is found that there is no significant effect in using the midpoint choice. It can be seen from the difference between the mean reliability with the midpoints (three and five options) and the mean reliability without the midpoints (four options). The mean of five options $=0.88497$, the mean of four options $=0.843895$, and the mean of three options $=0.822$. Thus, there is no decreasing significant reliability coefficients by using the midpoint options, it is different from what Rungson stated (2010: 399) in his invention that an options with the midpoint options will affect the variants, the variants are smaller because respondents will have more midpoints and they do not have to read or think the instruments they fill. Therefore, the reliability will decrease.

\section{CONCLUSION}

The average of the reliability coefficients for the instruments of belief about mathematics with five option numbers is higher than the reliability coefficients for the instruments of belief about mathematics with four option numbers. The average of the reliability coefficients for the instruments of belief about mathematics with five option numbers is higher than the reliability coefficients for the instruments of belief about mathematics with three option numbers. The average of the reliability coefficients for the instruments of belief about mathematics with four option numbers is higher than the reliability coefficients for the instruments of belief about mathematics with three option numbers. Thus, the more the option numbers are, the higher the reliability of the instrument will be.

\section{REFERENCE}


Anastasi Anne dan Susan Urbina. Tes Psikologi, terjemahan Robertus H. Imam. Jakarta: PT Prenhallindo, 1997.

Djaali dan Pudji Muljono. Pengukuran dalam Bidang Pendidikan. Jakarta: Grasindo, 2008.

Fatade, Alfred O., Abayomi A. Arigbabu, Mogari David, dan Adeneye A. "Investigating Senior Secondary School Students Beliefs About Further Mathematics In A Problem Based Learning Context." Bulgarian Journal of Science and Education Policy (BJSEP). http://bjsep.org/getfile.php?id=153 (accessed on November 19, 2014).

Kirkendall, Don R., Joseph J. Gruber, dan Robert E. Johnson. Measurement and Evaluation for Physical Educators. California: Brown Company Publisher, 1980.

Matic, Ljerka Jukic." Mathematical Knowledge of Non-Mathematics Students and Their Beliefs about Mathematics."

Mathematics Education, 2014, 9(1), 13 24. http://web.a.ebscohost.com/ehost/pdfvie wer/pdfviewer?vid=6\&sid=60dc4678-b2a6-43ee-a7bb-

1fb12656b52f\%40sessionmgr4003\&hid=4207 (accessed on November 19, 2014).

Mueller, Daniel J.Measuring Social Attitudes. New York: Teachers College, 1986.

Naga, Dali Santun. Teori Sekor Pada Pengukuran Mental. Jakarta: PT Naga Rani Citrayasa, 2013.

Rungson, Chomeya. "Quality of Psychology Test Between Likert Scale 5 and 6 Points.” Journal of Social Sciences. http://thescipub.com/PDF/jssp.2010.399.403.p df (accessed on November 28, 2014).

Schoenfeld, Alan H. "Learning to Think Mathematically: Problem Solving, Metacognition, and Sense-Making In Mathematics." didalam Handbook for Study on Mathematics Teaching and Learning, Editor. D. Grouws (New York: MacMillan, 1992).

Siti Muslihah Hadi. "Perbandingan Banyak Kategori Respon Terhadap Reliabilitas Instrumen Disposisi Matematika.”Tesis, PPs Universitas Negeri Jakarta: 2013.

Widhiarso,Wahyu. "Koefisien Reliabilitas untuk Pengukuran Multidimensi." http://elisa1.u gm.ac.id/files/wahyu_psy/Zb38uYZu/Widhiarso\%20\%20Koefisien\%20Reliabilitas \%20Untuk\%20Pengukuran\%20Multidimensi.pdf (accessed on November 23, 2014).

Wiersma, William dan Stephen G. Jurs.Educational Measurement and Testing. Boston: Allyn and Bacon, 1990. 